\title{
INTRAVESICAL PROSTAGLANDIN E2 EFFECTIVENESS IN THE PREVENTION OF URINARY RETENTION AFTER TRANSVAGINAL RECONSTRUCTION OF THE PUBO-CERVICAL FASCIA AND SHORT ARM SLING ACCORDING TO LAHODNY: A PROSPECTIVE RANDOMIZED CLINICAL TRIAL
}

\author{
G. QUADRI*, N. NATALE*, C. SPREAFICO*, C. BELLONI, \\ D. BARISANI* *, J. LAHODNY ${ }^{\circ}$
}

\author{
* MATERNAL-INFANTILE DEPARTMENT, GENERAL HOSPITAL - Lecco - Italy \\ - OBSTETRICS AND GYNECOLOGY DIVISION, VALDUCE HOSPITAL - Como - Italy \\ ** MEDICAL SCIENCE INSTITUTE, IRCCS, MAGGIORE HOSPITAL - Milano - Italy \\ $\circ$ GEBURTSHILFLICH-GYNAEKOLOGISCHE ABTEILUNG, A.O. KRANKENHAUS, St. Poelten
}

(Austria)

Key words: urinary retention, prostaglandin, cystocele, stress urinary incontinence, Lahodny procedure

\begin{abstract}
SUMMARY: Intravesical prostaglandin $E_{2}$ is effective in the recovery of spontaneous voiding after transvaginal reconstruction of the pubocervical fascia and short arm sling according to Lahodny. The aim of the study was to compare the effects of intravesical prostaglandin $E_{2}$ in the prevention of urinary retention after transvaginal reconstruction of the pubocervical fascia and short arm sling according to Lahodny. STUDY DESIGN: From November 1996 to June 1999 fifty women underwent the Lahodny procedure for moderate/severe cystocele and stress urinary incontinence. Women were randomly assigned to 1 of the 2 study groups: intravesical prostaglandin E2 versus controls. Data obtained were analyzed with the Student t test and the Fisher exact test. RESULTS: Two patients of the treatment group had to be excluded from the study, one because of the wrong measurement of the post-voidal residual volume and another due to a fastidious burning sensation which appeared immediately after prostaglandin instillation and required the suspension of the treatment. No other side effects such as nausea, vomiting, diarrhea or hyperthermia were observed. Patients who underwent the prostaglandin E2 treatment showed a recovery of spontaneous voiding after 7.9 9.7 days, whereas this interval was significantly longer in the

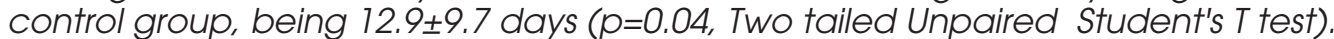
CONCLUSION: The effectiveness and the low associated morbidity mark the treatment with intravesical prostaglandin E2 useful in the recovery of normal voiding after transvaginal pubocervical fascia reconstruction and short arm sling with the procedure according to Lahodny.
\end{abstract}




\section{INTRODUCTION}

The slow recovery of spontaneous voiding after anterior colporrhaphy and transvaginal cystourethropexy represents a challenging problem both for patients and gynecologists. The need for prolonged postoperative bladder drainage results in patient distress, prolonged hospitalization, urinary infections and increased use of antibiotics.

There are several surgical techniques for anterior colporrhaphy, but they are not comparable because of the different anatomical structures affected by the procedure, as well as their ability to sustain the bladder neck and the urethra. The urethropexy procedure developed by Johann Lahodny (1) provides a good support for the bladder neck and the urethra, and thus is able to correct the stress urinary incontinence (SUI) due to hypermobility.

Various drugs acting on bladder and urethra contraction have been used in order to obtain a faster recovery of spontaneous voiding, but the results have not been satisfactory. The physiology of micturition is based on two mechanisms, namely the contraction of the detrusorial muscle fibers and the relaxation of the bladder neck and urethra muscle fibers (2). Cholinergic agonists cause bladder contraction through a direct inotropic effect on the detrusor muscle (3); however, drugs such as Bethanechol, induce bladder neck contraction at the same time. This side effect, associated with the rapid metabolic turnover of the drug, seriously limits its application in clinical practice (4). Alpha-lythic drugs are able to reduce urethral resistance, and thus can counteract the effect of cholinergic drugs on urethral tone (5). The combination of these two drugs has not provided the expected results on bladder function. In the last two decades, several studies investigated the effects of prostaglandin E1, E2, $\mathrm{F} 1 \alpha$ and $F 2 \alpha$ on bladder and urethra contraction, and on micturition (6-8). In particular, prostaglandin E2 efficacy on the recovery of spontaneous voiding has been demonstrated in patients with vaginal hysterectomy and cystourethropexy $(6,7)$, and after retropubic colposuspension (8).

The aim of this study was to evaluate, in an open randomized prospective clinical trial, the efficacy of prostaglandin E2 on the recovery of spontaneous voiding after vaginal hysterectomy and pubocervical fascia reconstruction using a short arm sling as described by Lahodny.

\section{PATIENTS AND METHODS}

From November 1996 to June 1999, 50 women with anterior vaginal prolapse (II and III degree) were assessed in the Urogynecology Unit of the Maternal-Infantile Department, Lecco General Hospital and at the Gynecological Division of Valduce Hospital, Como.

The preoperative and postoperative assessment included:

- gynecological and urological anamnesis, including the clinical score of subjective SUI according to the Monza score (9) (Table I)

- pelvic examination, including vaginal prolapse classification according to Beecham (10)

- stress test for objective SUI grading, according to Ferrari (1 1) (Table II)

- urethrocystoscopy

- Q-tip test

- uroflowmetry including postvoiding residual volume evaluation

- cystomanometry in the supine 
Table I - Subjective SUI score (Monza's Score)

\begin{tabular}{lcc}
\hline & 1 point & 2 points \\
\hline 1) condition & $\begin{array}{c}\text { coughing } \\
\text { sneezing } \\
\text { lifting weights } \\
\text { running } \\
\text { jumping }\end{array}$ & $\begin{array}{c}\text { coition } \\
\text { laughing } \\
\text { climbing stairs } \\
\text { walking }\end{array}$ \\
\hline 2) frequency & weekly & daily \\
\hline 3) quantity & $<=1$ pad/daily & $>=2$ pads/daily \\
\hline
\end{tabular}

multiply points as follow: $1-2=$ mild; $4=$ moderate; $8=$ severe

Table II - Objective SUI Score (Ferrari's Stress Test)

patients position during coughing

\begin{tabular}{lccc}
\hline & supine & erect \\
\hline $\begin{array}{l}\text { bladder } \\
\text { volume }\end{array}$ & $250 \mathrm{ml}$ & $\begin{array}{c}\text { IV class, } \\
\text { severe }\end{array}$ & $\begin{array}{c}\text { III class, } \\
\text { moderate }\end{array}$ \\
\cline { 2 - 3 } & $400 \mathrm{ml}$ & $\begin{array}{c}\text { II class, } \\
\text { mild }\end{array}$ & $\begin{array}{c}\text { I class, } \\
\text { very mild }\end{array}$ \\
\end{tabular}

position with saline infusion (at a filling rate of $100 \mathrm{ml} / \mathrm{min}$ ) using a dual microtip catheter in the bladder and a single microtip catheter in the upper part of the vagina (Dantec Instruments).

- urethral pressure profilometry, at rest and during stress, in the supine position using a dual microtip catheter (Dantec Instruments) and $250 \mathrm{ml}$ of isotonic saline solution in the bladder .

Hypermobility of the bladder neck was defined at the Q-tip test as the presence under stress of an angle $>30^{\circ}$ compared to the horizon, plus a rotation of $>30^{\circ}$ between the rest position and that observed after the Valsalva maneuver.

After a clinical and urodynamic evaluation, all patients underwent vaginal hysterectomy with reconstitution of the pubocervical fascia and short arm sling according to Lahodny. Women with chronic urinary retention, pre-operative detrusor instability, bladder neuropathy, urinary tract infections (active or recurrent), asymptomatic bacteriuria, known allergy to prostaglandins or any other allergy were excluded from the study.

All surgical procedures were performed by the house staff of the 
two Urogynecological units participating in this study. All patients received prophylactic cephazolyn sodium (1 gram i.v.) 30 minutes before surgery. Antithromboembolic prophylaxis with low molecular weight heparin was administered the morning on which surgery was performed and then continued for 5 days. For two days after surgery a suprapubic catheter (Cistofix, Braun Melsungen - Germany) was left in place for continuous bladder drainage. Starting from the third day, the catheter was clamped for three hours, and the patient was invited to void with a full bladder. All patients were discharged on day 7; if a postvoided residual volume of $>50 \mathrm{ml}$ was observed, the cystostomic catheter was left in place and the patient was requested to keep a diary in which she recorded the voided volume and the post-voided residual volume. Whenever the latter was $<50 \mathrm{ml}$, the patient was seen in the outpatient clinic for the removal of the catheter.

The patients were divided into two groups (prostaglandin treatment and controls) according to a computergenerated randomization table. The patients assigned to the prostaglandin group were treated with $1.5 \mathrm{mg}$ of Dynoprostone (2 vials of Prostin E2, Pharmacia \& Upjohn, Puurs, Belgium) starting 48 hours after surgery. The drug was diluted in $5 \mathrm{ml}$ of saline solution and injected into the bladder through the catheter, which was then clamped for at least 1 hour. Prostaglandin treatment was administered once a day up to five consecutive days.

The terminology employed in the paper, unless otherwise stated, is in accordance with the guidelines approved by the International Continence Society.
Two-tail Fisher test and two-tail Student's T-test for independent group of data were employed, when appropriate, for the statistical analysis.

SURGICAL TECHNIQUE: Anterior median longitudinal colpotomy is performed and the lamina vasorum is reached by passing between the vaginal wall and the vaginal sectum (pubo-cervical fascia). The lamina vasorum constitutes the inferior prevesical fascia which hosts the inferior vesical artery, vein and nerve; after its exposure, a blunt dissection is performed near the pubo-coccigeal portion of the levator muscle aponeurosis employing a Pean clamp, penetrating for $\sim 8 \mathrm{~cm}$ in the direction of lamina membranacea, (tendineous arc of the endopelvic fascia). The space obtained after this procedure (spatium vesico-pelvinum) is delimited by the tendineous arc which constitutes the lateral and cranial border, and caudally by the vesical-uterine ligaments. The bladder wall between the lamina vasorum and lamina membranacea is covered by a fascial part called the lamina coniugans, which represents the median border of the spatium vesico-pelvinum, whereas the pubococcygeal muscle aponeurosis encloses it laterally.

The small fibrous sects present in the virtual space between lamina coniugans and the aponeurosis of the pubococcygeal muscle are removed by hand. The dissection maneuver causes the interruption of some of the inferior vesical nerve fibers.

The two lamina vasorum are brought together in the midline and sutured with 6-8 interrupted Vicryl sutures to eliminate the hiatus which caused the bladder and bladder 
neck hernia. The urethrotendineous ligaments are then sutured on the midline below the bladder neck, followed by a partial suture of the posterior pubo-urethral ligaments which are easily identified after the suture of the lamina vasorum. A "short arm sling" is thus created, a structure which raises and sustains the urethro-vesical junction, repositioning it on the same level of the tendineous arc of the endopelvic fascia (12). Anterior colporrhaphy using interrupted 0 Vicryl suture concludes the operation.

\section{RESULTS}

Fifty patients were enrolled in the study; 25 received intravesical prostaglandins, whereas 25 constituted the control group. Twenty-six women reported stress urinary incontinence (SUI), whereas stress incontinence was elicited in other 20 women after the stress test. Four women were subjectively and objectively continent. Preoperative clinical data and objective grading of genital prolapse, as well as subjective and objective grading of SUl are shown in Table 3 and 4 respectively. No significant difference was observed in the preoperative data or subjective SUl grading of the patients assigned to either group, while a higher number of continent patients were in class IV (Ferrari stress test) in the PGE2 group.

Two patients of the treatment group had to be excluded from the study, one because of the wrong measurement of the post-voidal residual volume and another due to a fastidious burning sensation which appeared immediately after prostaglandin instillation and required the suspension of the treatment.

Table III - Preoperative clinical data

\begin{tabular}{lccc} 
& controls & PGE2 & P value \\
\hline N. pts. & 25 & 23 & \\
\hline Age (Yrs \pm SD) & $61.6 \pm 10.5$ & $65.2 \pm 7.6$ & $0.17^{*}$ \\
\hline Parity (N. \pm SD) & $2.3 \pm 0.7$ & $2.4 \pm 1.4$ & $0.78^{*}$ \\
\hline Postmenopausal (N.) & 21 & 21 & $0.37 \wedge$ \\
\hline Body Mass Index (mean \pm SD) & $24 \pm 1.5$ & $24.3 \pm 1.7$ & $0.53^{*}$ \\
\hline Subjective SUl Score (mean \pm SD) & $1.5 \pm 1.7$ & $1.2 \pm 1.6$ & $1^{*}$ \\
\hline Stress Test Class (mean) & $3.2 \pm 1.4$ & $3.2 \pm 1.5$ & $1^{*}$ \\
\hline Q-tip test at straining & $52.5 \pm 20.7$ & $58.2 \pm 24$ & $0.57^{*}$ \\
(mean \pm SD; degrees) & & & \\
\hline Cystocele II degree (n.) & 12 & 11 & $0.60 \wedge$ \\
\hline Cystocele III degree (n.) & 13 & 12 & $0.60 \wedge$ \\
\hline
\end{tabular}

* Umpaired Student's T Test ; ^ Fisher's Exact Test 
Table IV - Subjective and objective grading of SUI (preoperative, $n^{\circ}$ pts.)

\begin{tabular}{|c|c|c|c|c|c|c|c|c|}
\hline \multirow{3}{*}{ grade } & \multicolumn{2}{|c|}{$\begin{array}{l}\text { subjective SUI } \\
\text { (MONZA SCORE) }\end{array}$} & \multicolumn{6}{|c|}{$\begin{array}{c}\text { objective SUI } \\
\text { (FERRARI STRESS TEST) }\end{array}$} \\
\hline & \multirow[t]{2}{*}{ controls } & \multirow[t]{2}{*}{ PGE2 } & \multicolumn{3}{|c|}{ controls } & \multicolumn{3}{|c|}{ PGE2 } \\
\hline & & & neg & III & IV & neg & III & IV \\
\hline continent pts. & 10 & 14 & 2 & 2 & 6 & 2 & / & 12 \\
\hline mild SUI & 11 & 6 & 2 & 1 & 8 & 2 & 1 & 3 \\
\hline moderate SUI & 3 & 3 & / & I & 3 & / & 1 & 2 \\
\hline severe SUI & 1 & I & I & I & 1 & I & / & I \\
\hline total & 25 & 23 & 4 & 3 & 18 & 4 & 2 & 17 \\
\hline
\end{tabular}

Table V - Preoperative urodynamic data

\begin{tabular}{lccc}
\hline & controls & PGE2 & P value \\
\hline Peak flow $(\mathrm{ml} / \mathrm{sec})$ & $23.9 \pm 9.8$ & $21.8 \pm 6$ & 0.41 \\
\hline Mean flow $(\mathrm{ml} / \mathrm{sec})$ & $10.7 \pm 4.3$ & $9.8 \pm 3.2$ & 0.42 \\
\hline Flow time $(\mathrm{sec})$ & $32.2 \pm 15.8$ & $38 \pm 22.2$ & 0.31 \\
\hline Urethral functional length $(\mathrm{mm})$ & $21.8 \pm 4.8$ & $22.6 \pm 4.7$ & 0.54 \\
\hline Max. urethral closure pressure $(\mathrm{cm} \mathrm{H} 2 \mathrm{O})$ & $47.1 \pm 22.9$ & $37.6 \pm 16.8$ & 0.11 \\
\hline
\end{tabular}

Unpaired Student's T Test. Values are mean \pm SD

Table VI - Resumption of postoperative spontaneous voiding

\begin{tabular}{lccc}
\hline & controls & PGE2 & P value \\
\hline removal of catheter (days) & $12.9 \pm 9.7$ & $7.9 \pm 6.7$ & 0.04 \\
\hline
\end{tabular}

Two-Tailed Umpaired Student' T Test; values are mean \pm SD 
Four other patients reported a mild burning sensation few minutes after prostaglandin administration, but it did not require the interruption of the study. No side effects such as nausea, vomit, diarrhea or hyperthermia were observed.

Patients who underwent the PGE2 treatment showed a recovery of

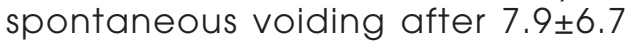
days, whereas this interval was significantly longer in the patients belonging to the control group, being $12.9 \pm 9.7$ days ( $p=0.04$, Two tailed Unpaired Student's T Test).

\section{DISCUSSION}

The technique proposed by Johann Lahodny is normally characterized by a slow recovery of spontaneous voiding, as already reported by the original paper (1). This fact could be justified by the surgical procedure itself, which requires large detachments that may cause the lesion of some of the inferior vesical nerve fibers .

Baudino (13) observed a high prevalence of post-operative urinary retention after Lahodny's procedure, with a recovery of normal voiding after 12.5 days, data comparable to those obtained in the present study (12.9 days). These data also confirm that Lahodny's technique can cause more prolonged urinary retention than the well-known Kelly-Kennedy cystourethropexy $(6,7)$, where recovery of spontaneous voiding usually occurs at 6-8 days after surgery. Furthermore, this evidence supports the need for drugs which can prevent or treat post-operative urinary retention.

Several studies have demonstrated that prostaglandin E2 can cause the contraction of the longitudinal vesical muscles $(14,15,16,17)$ and a relaxation of the circular urethral muscle fibers (18), unlike what has been observed for other prostaglandins such as F2 $\alpha$ (19), that causes a contraction of the urethral muscles. Thus these physiologic data prompted various investigators to assess the efficacy of different prostaglandins in patients with urinary retention. Jaschevatzky (20) observed an increase in detrusor pressure of $40 \%$ using intravesical instillation of PGF2 $\alpha$ in women who underwent vaginal hysterectomy.

Koonings (8) demonstrated the efficacy of the early administration of $10 \mathrm{mg}$ PGE2 in reducing urinary retention after retropubic colposuspension, without any major side effects.

Scalambrino et al (6) obtained a significant shortening of the recovery time in patients with anterior colporrhaphy after an early intravesical administration of $1.5 \mathrm{mg}$ of dynoprostone (PGE2) diluted in 50 $\mathrm{ml}$ of saline solution. These data were also supported by Bergman et al (7), who observed a significant improvement in spontaneous voiding after treatment with $3 \mathrm{mg}$ PGE2 in women with anterior and posterior colporrhaphy. Interestingly, the study by Wagner et al (21) suggested that the time of prostaglandin administration could play a role in its efficacy, which was markedly decreased when the treatment was delayed (6-7 postoperative days).

At the present time there are no data on the use of PGE2 to facilitate the recovery of spontaneous voiding after the Lahodny procedure. In this randomized study on patients with vaginal hysterectomy followed by vaginal reconstruction according to Lahodny, intravesical PGE2 administration significantly improved 
the recovery of spontaneous voiding, with a reduction of approximately $40 \%$. Intravesical PGE2 instillation was preferred, since the presence of a suprapubic catheter already in place allowed the administration of the drug with minimal discomfort for the patients.

The therapeutic effect of PGE2 could be due to the stimulation of the sensory terminations present in the epithelium of the urinary tract, which in turn could cause a reflex contraction of the bladder detrusor muscle. In vitro and in vivo data have demonstrated that the efficacy of PGE2 is concentration-dependent $(19,22)$, and therefore we diluted the drug in a final volume smaller than those previously reported $(6,7,8)$ in order to improve its efficacy. However, we could not perform a direct comparison of two different final volumes because of the number of patients enrolled, and further studies will be necessary to confirm this hypothesis.

In summary, the data obtained in this group of patients support the efficacy of an early administration of PGE2 even in case of Lahodny's procedure. In fact, as previously demonstrated by two different groups (21), late administration of the drug is associated to low efficacy, since an over-distension of the bladder muscular fibers is already present. A prophylactic administration of PGE2 should thus be recommended 24-48 hours after surgery, before an irreversible distension of the muscular fibers takes place. PGE2 treatment could represent an important tool in the management of postoperative urinary retention, even after surgical procedures which require large bladder detachments.

corresponding author:

Giorgio Quadri MD

via Pretorio n, 3 - 22100 Como, Italy

home telephone: 0039-031-302645

hospital fax: 0039-0341-489250

\section{REFERENCES}

1 - LAHODNY J:

Vaginale Inkontinenz-und Deszensuschirurgie, F. Enke Verlag Stuttgart 1991

2 - BRADLEY WE:

The neurology of micturition - in Gynecology Urology and Urodynamics 1980; chapter II:17-50 Edited by Ostergard DR, William \&Wilkhins, Baltimore

3 - FINKBEINER AE:

Is Bethanechol chloride clinically effective in promoting bladder emptying? Journal of Urology 1985; 134: 443-449

4 - BARRET DM:

The effect of oral bethanechol chloride on voiding in female patients with excessive residual urine: a randomized double blind study. J.Urol 1981; 126:640-642. 
5 - YALLA SB, ROSSIER AB, FAM BA et al:

Functional contribution of autonomic innervation to urethral striated sphincter: studies with parasympathomimetic, parasympatolytic and alphadrenergic blocking agents in spinal cord injury and control male subjects. Journal of Urology, 1977; 494-499.

6 - SCALAMBRINO S, COLOMBO M, MILANI R et al:

Intravesical prostaglandin E2 in the prevention of urinary retention after anterior vaginal repair.

Urodinamica 1994; 4: 335-336.

7 - BERGMAN A, MUSHEKET Y, GORDON D et al:

Prostaglandin prophylaxis and bladder function after vaginal hysterectomy: a prospective randomised study.

Br.J.Obstet.Gynecol 1993; 100:69-72.

8 - KOONINGS PP, BERGMAN A, BALLARD CA:

Prostaglandins for enhancing detrusor function after surgery for stress incontinence in women.

The Journal of Reproductive Medicine 1990; 35: 1-5

9 - COLOMBO M, SCALAMBRINO S, MAGGIONI A, MILANI R.:

Burch colposuspension versus modified Marshall-Marchetti-Krantz urethropexy for primary genuine stress urinary incontinence: A prospective, randomised clinical trial.

Am. J. Obstet. Gynecol. 1994; 171: 1573-1579.

10 - BEECHAM CT:

Classification of vaginal relaxation.

Am. J. Obstet. Gynecol. 1980; 136 : 957- 958.

11 - FERRARI A:

A grading model for stress urinary incontinence.

Urology 1986; 27:76-78.

12 - IMPARATO E:

Corso di chirurgia ricostruttiva vaginale (atti)- II Congresso Nazionale AIUG Associazione Italiana di Urologia Ginecologica. Roma 4-7 marzo 1992.

13 - BAUDINO G, ROCCHI B, PICERNO U et al:

The Lahodny pelvic reconstruction procedure: anatomic and functional results.

Urogynaecologia International Journal 1998;12;1:15-22

14 - PERSSON CGA:

Inhibitory effect at the bladder-urethral junction.

Acta Physiol. Scand 1976, 97:139-141.

15 - ABRAMS PH, FENELEY RCL:

The action of prostaglandins on the smooth muscle of the human urinary tract in vitro. Br. J. Urol. 1976; 47: 909-.

16 - LARSON C:

Effects of prostaglandins on the field-stimulated rat isolated urinary bladder.

Prostaglandins 1978; 15: 701.

17 - BISSADA NK:

Need for a new class of drugs to induce or augment micturition.

Urology 1979; 14:104-105. 
18 - GHONEIM MA, FRETIN JA, GAGNON DG:

The influence of vesical distention on the urethral resistance to flow: a possible role for prostaglandins?

Journal of Urology 1976; 116: 739-743.

19 - ANDERSON KE, FORMAN A:

Effects of Prostaglandins on the Smooth Muscle of the Urinary Tract.

Acta pharmac. et toxicol. 1978; 43(II), 90-95.

20 - JASCHEVATZKY OE, ANDERSMAN S, SHALIT A, et al:

Prostaglandins $\mathrm{F} 2 \mathrm{a}$ for prevention of urinary retention after vaginal hysterectomy. Obstet. Gynecol 1985;66: 244-247.

21 - WAGNER G, HUSSLEIN P, ENZELSBERGER:

Is prostaglandin E2 really of therapeutic value for postoperative urinary retention? Results of a prospectively randomized double-blind study.

Am. J. Obstet. Gynecol .1985; 15: 375

22 - KHALAF MI, RIOUX F, QUIRION R, ELHILALI MM:

Intravesical prostaglandin: release and effect of bladder instillation on some micturition parameters.

British J. of Urology 1980: 52; 351-356. 